\title{
The United States Drug Enforcement Administration and Prescription Opioid Production Quotas: An End Game of Eradication?
}

This article was published in the following Dove Press journal:

Journal of Pain Research

\author{
Michael E Schatman $\mathbb{D}^{1,2}$ \\ Erica L Wegrzyn ${ }^{3}$ \\ 'Department of Diagnostic Sciences, \\ Tufts University School of Dental \\ Medicine, Boston, MA, USA; \\ ${ }^{2}$ Department of Public Health and \\ Community Medicine, Tufts University \\ School of Medicine, Boston, Ma, USA; \\ ${ }^{3}$ Department of Pharmacy, Stratton VA \\ Medical Center, Albany, NY, USA
}

Correspondence: Michael E Schatman Tel +I 425 647-4880

Email Michael.Schatman@tufts.edu
As a means of mitigating the now concluded prescription opioid crisis in the United States, the Drug Enforcement Administration (DEA) has, in its infinite wisdom, embarked on a campaign of annually reducing the Aggregate Production Quota (APQ) of opioids each year since 2017. According to the DEA, they began reducing the APQ because there was no longer the need for a $25 \%$ "buffer" of excess opioids due to decreases in prescribing each year. ${ }^{1}$ In 2017 , production of almost every opioid manufactured in the United States was reduced by at least $25 \% .{ }^{1}$ In 2018 , APQs of opioids - including oxycodone, hydrocodone, oxymorphone, hydromorphone, morphine, codeine, meperidine, and fentanyl - were reduced by $20 \%$ compared to 2017 production. $^{2}$ For 2019, DEA reduced APQs only of "more commonly prescribed schedule II opioids, including oxycodone, hydrocodone, oxymorphone, hydromorphone, morphine, and fentanyl". ${ }^{3}$ The 2020 production decreases affected 5 commonly-used opioids: Oxycodone production was decreased by $9 \%$, hydrocodone by $19 \%$, hydromorphone by $25 \%$, fentanyl by $31 \%$, and oxymorphone by $55 \%{ }^{4}$ Given, in response to the need for increased availability of opioids associated with the COVID-19 crisis, DEA made small adjustments (increases of 10-15\%) in production APQs in April of 2020 of analgesics including codeine, fentanyl, hydromorphone, and morphine. ${ }^{5}$ Unfortunately, this action was too little, too late. Hospitals that had already been sounding the alarm for the past several years regarding routine shortages of parenteral opioids suddenly were faced with inadequate supplies essential for treating patients on ventilators amidst COVID-19, with the need for IV formulations increasing more than twofold. ${ }^{6}$

By 2020, DEA reported that total domestic opioid production had decreased by $53 \%$ since $2016 .^{4}$ Irrespective, DEA recently released its proposed production decreases for 2021, which include an additional 20\% reduction of fentanyl, a $15 \%$ reduction of oxycodone, a $12 \%$ decrease of hydrocodone, and a $9 \%$ reduction of hydromorphone, all compared to the original figures for 2020. Curiously, the proposed APQ of oxymorphone actually increased by $13 \%$ compared to the original APQ for 2020, keeping its level of production unchanged from the April, 2020 adjustment. ${ }^{7}$ This most recent proposed APQ is bewildering, given that half a year ago, DEA felt compelled to adjust its APQs in response to a pandemic which is hardly over, with no certainty regarding the course that it will take. While April's manufacturing increase may have provided a temporary fix, concern has been raised 
that years of annual reductions have left manufactures at max capacity, with limited ability for additional production surges, and supply chains described as 'fragile'. 6

By early 2018, Bruera noted a "severe and immediate" shortage of parenteral morphine, hydromorphone, and fentanyl in cancer treatment centers across the country, attributing the shortage, at least in part, to the DEA's APQ reductions. ${ }^{8}$ The author noted the stress that this shortage placed not only on patients with pain, but on those who treat them as well, and further noted the ethical implications of the reductions. Just weeks later, Hollingsworth and Herndon echoed Dr. Bruera's concerns in a compelling editorial. ${ }^{9}$ In 2019, Haider and colleagues published a formal study, attributing oncologists' need to substitute parenteral opioids as well as oral hydrocodone and oxycodone for the preferred morphine and hydromorphone due to the reductions of APQs perpetrated by the DEA. ${ }^{10}$ The authors found that while total daily opioid dosages increased, fewer patients in their study achieved adequate pain control. This is, in effect, "deprescribing without a license" by denying access to medications which may be safer when considering differences in pharmacology with Phase I metabolism (hydrocodone and oxycodone) versus Phase II metabolism (hydromorphone and morphine) and potential for comorbidities. ${ }^{11}$ Other subsequent commentaries and studies have confirmed the challenges associated with treating inpatients' pain due to the APQ reductions, ${ }^{12-18}$ including those addressing treating children perioperatively and postoperatively. ${ }^{19,20}$

$\mathrm{Up}$ to this point, reports of APQ reduction-related shortages of oral opioids are only anecdotal, with numerous reports from patients on social media. In these cases, the patients (generally suffering from chronic non-cancer pain) report that their pharmacies have "run out" of medications that they have taken for many years, although these patients have not been privy to whether these lacks of availability are due to APQ reductions or other supplyside issues within their own pharmacies. Irrespective this has the potential of creating a dangerous bias against legitimate opioid patients who may have to go to multiple pharmacies and travel great distances for needed medications. We are concerned that should production continue to decrease as precipitously as has been the case over the past several years, all of the United States may turn into an "opioid desert". Further, we believe that the climate of opiophobia in the United States is progressively causing unnecessary harms to chronic pain sufferers, and that continued production reductions will potentially serve only to make these patients more miserable. Social media is rife with discussions of the "haves" and the "have nots", strongly suggesting that only chronic pain sufferers who are "connected" in some manner are able to receive and benefit from opioid analgesia. Ethically, this situation presents quite an imbroglio. As Cheng recently noted, medical opioid shortages make social discrimination essentially inevitable, particularly in a socially divisive culture such as that in the United States. ${ }^{21}$ In the current case of DEA's persistent reductions of APQs of opioids, not only is the government failing to mitigate such social discrimination, but is also potentially exacerbating it.

DEA did its job a number of years ago, shutting down the "pill mills" that proliferated in the United States that fueled considerable diversion resulting in myriad overdose deaths. However, at this point, there is no evidence that their APQ-reduction policies are benefiting anyone, while palliative care specialists are convinced that they are causing considerable harm. Need they continue with this trend to the point that both acute and chronic pain sufferers are forced to go without quality of life-sustaining treatment that they often so desperately need? DEA is tasked with making American society safe from all drugs of potential abuse, and continue to prosecute physicians, other prescribers, and pharmacies for what they consider "irresponsible behavior" within the context of their professions. ${ }^{22}$ However, its program of eradicating access to prescription opioids for those who need them is a case of failure to "stay in their lane", as their defined role is to protect the public, not punish its citizens who suffer from the unfortunate disease of chronic pain.

\section{Disclosure}

This article is the sole work of the authors, and stated opinions/assertions do not reflect the opinion of employers or employee affiliates. It was not prepared as part of either authors' duty as a federal employee. The authors report no other relevant conflicts of interest in this work.

\section{References}

1. United States Drug Enforcement Administration. DEA reduces amount of opioid controlled substances to be manufactured in 2017; October 4, 2016. Available from: https://www.dea.gov/press-releases/2016/10/04/ dea-reduces-amount-opioid-controlled-substances-be-manufactured -2017. Accessed September 15, 2020.

2. United States Drug Enforcement Administration. DEA proposes reduction to amount of controlled substances to be manufactured in 2018; August 4, 2017. Available from: https://www.dea.gov/pressreleases/2017/08/04/dea-proposes-reduction-amount-controlledsubstances-be-manufactured-2018. Accessed September 15, 2020. 
3. United States Drug Enforcement Administration. Justice Department, DEA propose significant opioid manufacturing reduction in 2019; August 16, 2019. Available from: https://www.dea.gov/pressreleases/2018/08/16/justice-department-dea-propose-significantopioid-manufacturing-reduction. Accessed September 15, 2020.

4. United States Drug Enforcement Administration. DEA proposes to reduce the amount of five opioids manufactured in 2020, marijuana quota for research increases by almost a third; September 11, 2019. Available from: https://www.dea.gov/press-releases/2019/09/11/deaproposes-reduce-amount-five-opioids-manufactured-2020-marijuanaquota. Accessed September 28, 2020.

5. United States Drug Enforcement Administration. Adjustments to aggregate production quotas for certain schedule II controlled substances and assessment of annual needs for the list i chemicals ephedrine and pseudoephedrine for 2020, in response to the coronavirus disease 2019 public health emergency; April 10, 2020. Available from: https://www.deadiversion.usdoj.gov/fed_regs/quotas/2020/ fr0410.htm. Accessed September 28, 2020.

6. Girion L, Levine D, Respaut R.Special report: COVID deepens the other opioid crisis - a shortage of hospital painkillers. Reuters healthcare \& pharma; June 9,2020. Available from:https:/www.reu ters.com/article/us-health-coronavirus-opioids-specialrep/specialreport-covid-deepens-the-other-opioid-crisis-a-shortage-of-hospitalpainkillers-idUSKBN23G1GM. Accessed October 6,2020.

7. United States Drug Enforcement Administration. Proposed aggregate production quotas for schedule $\mathrm{i}$ and ii controlled substances and assessment of annual needs for the list I chemicals ephedrine, pseudoephedrine, and phenylpropanolamine for 2021; September 1, 2020. Available from: https://www.federalregister.gov/documents/2020/09/01/202019285/proposed-aggregate-production-quotas-for-schedule-i-and-iicontrolled-substances-and-assessment-of. Accessed September 28, 2020.

8. Bruera E. Parenteral opioid shortage - treating pain during the opioid-overdose epidemic. N Engl J Med. 2018;379(7):601-603. doi:10.1056/NEJMp1807117

9. Hollingsworth H, Herndon C. The parenteral opioid shortage: causes and solutions. J Opioid Manag. 2018;14(2):81-82. doi:10.5055/ jom.2018.0434

10. Haider A, Qian Y, Lu Z, et al. Implications of the parenteral opioid shortage for prescription patterns and pain control among hospitalized patients with cancer referred to palliative care. JAMA Oncol. 2019;5(6):841-846. doi:10.1001/jamaoncol.2019.0062
11. Smith HS. Opioid metabolism. Mayo Clin Proc. 2009;84(7):613-624. doi:10.1016/S0025-6196(11)60750-7

12. Dalal S, Bruera E. Pain management for patients with advanced cancer in the opioid epidemic era. Am Soc Clin Oncol Educ Book. 2019;39:24-35.

13. Wang B, Downing NL. A crisis within an epidemic: critical opioid shortage in US hospitals. Postgrad Med J. 2019;95(1127):515-516. doi:10.1136/postgradmedj-2018-136058

14. Terry NP. The opioid litigation unicorn. SC Law Rev. 2019;70:637-666.

15. Reardon CE, Kane-Gill SL, Smithburger PL, Dasta JF. Sufentanil sublingual tablet: a new option for acute pain management. Ann Pharmacother. 2019;53(12):1220-1226. doi:10.1177/10600280198 63144

16. Kim DE, Pruskowski KA, Ainsworth CR, Linsenbardt HR, Rizzo JA, Cancio LC. A review of adjunctive therapies for burn injury pain during the opioid crisis. J Burn Care Res. 2019;40(6):983-995. doi:10.1093/jbcr/irz111

17. Salajegheh R, Nemergut EC, Rice TM, et al. Impact of a perioperative oral opioid substitution protocol during the nationwide intravenous opioid shortage: a single center, interrupted time series with segmented regression analysis. PLoS One. 2020;15(6): e0234199. doi:10.1371/journal.pone.0234199

18. Tran KK, VanDaele MA, Tran S, Stevens SA, Maltese Dietrich N, Franck AJ. Evaluation of acute postoperative pain management during an injectable opioid shortage. Ann Pharmacother. 2020;106002 8020962037. doi:10.1177/1060028020962037

19. Franz AM, Dahl JP, Huang H, et al. The development of an opioid sparing anesthesia protocol for pediatric ambulatory tonsillectomy and adenotonsillectomy surgery-A quality improvement project. Paediatr Anaesth. 2019;29(7):682-689. doi:10.1111/pan.13662

20. Barnes TA, Feng HX, Herrera NA, Leathers LA. The impact of intravenous opioid shortages on postoperative pain control in a pediatric cardiac intensive care unit. J Card Surg. 2020;35 (4):840-844. doi:10.1111/jocs. 14492

21. Cheng B. Disparities in access to palliative medication: the duty of the state to ensure opioid medication access. Penn Bioeth J. 2018;8 (2):10-14.

22. United States Drug Enforcement Administration. Registrant Actions; 2020. Available from: https:/www.deadiversion.usdoj.gov/fed_regs/ actions/2020/index.html. Accessed September 28, 2020.
Journal of Pain Research

\section{Publish your work in this journal}

The Journal of Pain Research is an international, peer reviewed, open access, online journal that welcomes laboratory and clinical findings in the fields of pain research and the prevention and management of pain. Original research, reviews, symposium reports, hypothesis formation and commentaries are all considered for publication. The manuscript

Submit your manuscript here: https://www.dovepress.com/journal-of-pain-research-journa management system is completely online and includes a very quick and fair peer-review system, which is all easy to use. Visit http:// www.dovepress.com/testimonials.php to read real quotes from published authors. 